\title{
NIETZSCHE, O PSICÓLOGO DA DESCONSTRUÇÃO DO SUJEITO. A VISÃO DE UM DEUS NÃO MORAL
}

\author{
Adilson Felicio Feiler ${ }^{1}$ \\ Universidade do Vale do Rio dos Sinos ( UNISINOS) \\ https://orcid.org/0000-0001-7352-927X \\ E-mail: afeiler@unisinos.br
}

\section{RESUMO:}

Por traz das críticas de Nietzsche à moral, ele tem no Cristianismo do movimento messiânico de Jesus um antídoto contra o niilismo. Promotor de um ethos cristão, o Cristianismo, que, em fidelidade ao seu espírito crístico, faz consistir seus ensinamentos não apenas numa lei ou dogma doutrinal, mas principalmente numa prática de vida ao assumir o seu destino com amor. Acolhe o destino de maneira não resignada ou conformista, mas com disposição ativa. $O$ espírito cristão de Jesus consiste na sua prática, da qual decorre a desconstrução do sujeito moral. É uma prática que, ao invés de se resignar passivamente ao destino como foi a tradição cristã, o assume até as suas últimas consequências em que a vida, atinge os seus pontos mais culminantes.

PALAVRAS-CHAVE: Nietzsche; Filosofia; Moral; Cristianismo; Prática.

\section{NIETZSCHE, THE PSYCHOLOGIST OF SUBJECT DECONSTRUCTION. THE VIEW OF A GOD NOT MORAL}

\begin{abstract}
:
Through Nietzsche's criticism of morality, he has in Christianity a messianic movement of Jesus an antidote against nihilism. Promoter of a Christian ethos, the Christianity, which, in fidelity to his Christic spirit, makes his teachings consist not only of a doctrinal law or dogma, but mainly of a life practice in assuming his destiny with love. He accepts destiny in a non-resigned or conformist way, but with an active disposition. The Christian spirit of Jesus consists in his practice, from which the deconstruction of the moral subject takes place. It is a practice that, instead of being passively resigned to fate as was the Christian tradition, assumes it until its last consequences in which life reaches its climaxes.
\end{abstract}

KEYWORDS: Nietzsche; Philosophy; Moral; Christianity; Practice.

\footnotetext{
${ }^{1}$ Doutor em Filosofia pela Pontifícia Universidade Católica do Rio Grande do Sul (PUCRS), Porto Alegre - RS, Brasil. Professor colobarodor do Programa de Pós-Graduação em Filosofia da Universidade do Vale do Rio dos Sinos ( UNISINOS), São Leopoldo - RS, Brasil.
}

FEILER, Adilson Felicio. Nietzsche, o psicólogo da desconstrução do sujeito. A visão de um deus não moral. Griot : Revista de Filosofia, Amargosa - BA, v.18, n.2, p.34-42, dezembro, 2018. 


\section{Introdução}

A universalidade e a singularidade da vida atestam seu caráter de plenitude, portanto, de abertura para se atingir pontos culminantes de potência que implicam na quebra de estruturas cristalizadas na lei positiva; com isso, o destino deixa de ser rejeitado como estranho, para ser assumido com amor. A vida, assim compreendida, se desprende de todas aquelas estruturas fortes que até então, segundo Nietzsche, eram consagradas pela cultura ocidental.

Nietzsche, se apresenta como aquele que considera a modernidade um problema, ao desacreditar na existência de verdades eternas, consideradas produtos passageiros de um tempo histórico em que urge o desmascaramento das ciências humanas pela crítica da razão.

Nietzsche, ao apresentar um novo modo de ser no mundo, marcado pela perda de uma autoridade absoluta e eterna, enaltece a prática de vida inaugurada com Jesus de Nazaré, revela simpatias por Jesus (KÜNG, 1976, p. 349).

Assim, para além de simplesmente pensar Nietzche como aquele que abre as portas ao ateísmo na modernidade, bem como a radicaliza pela sua iconoclastia, tal como os nietzschianos pós-modernos até então o tem concebido, o problema do Cristianismo é uma realidade que provoca, deixando-se afetar pela vivência religiosa cristã, tanto em sua afirmação quanto em seu rechaço, da figura de Jesus. No nazareno a reconciliação entre os polos da tensão dialética e a transvaloração dos valores encontram a culminância pela sua paixão da unidade de todo o existente, que reintegra em uma unidade superior todas as antinomias, permitindo pensar um novo horizonte messiânico para a humanidade que não se espera acontecer, mas se faz. $\mathrm{O}$ messianismo da prática de Jesus é original, critica e reconcilia. Este apresenta a prática de Jesus que se depreende do Evangelho de João: o Evangelho que, ao acentuar a prática de unidade em plenitude pelo movimento espiritual do Logos, reflete a soberania daquele que é responsável por ela. Soberania esta que se expressa de modo particular em sua ética do amor fati, uma ética do "Sim" para além de uma vida não degenerada pelo Cristianismo dogmático e pela filantropia moderna, da compaixão.

Por mais que se apresentem obstáculos causadores de inúmeros sofrimentos, estes não subjugam, pois, todas estas forças que fazem sofrer não são estranhas àqueles que as experimentam, mas estão relacionadas a sua singularidade de vida. A sua postura, neste sentido, é aquela que assume o destino, como em Nietzsche, apresentando o seu conceito de amor: a acolhida jubilosa à vida, ao destino: amor fati, que é a sua ética, a sorte da vida daqueles que não se resignam à felicidade dos fracos, mas que se lançam, com valentia e coragem, frente às situações adversas.

Apresentamos nossa investigação em três capítulos. No primeiro apresentamos, em linhas gerais, elementos que se depreedem da prática histórica de Jesus de Nazaré, aproximando sua prática àquilo que Nietzsche compreende enquanto espírito cristão, para além de sua falsificação propugnada pelos que se apropriaram e instrumentalizaram o conteúdo de sua pregação. Na sequência, apresentamos em que medida a ética afirmativa, que se depreende da prática de Jesus, é capaz de superar o niilismo. Para, no terceiro e último capítulo, mostrarmos alguns pontos de crítica à Nietzsche sobre o contrassenso que pode se depreender do

FEILER, Adilson Felicio. Nietzsche, o psicólogo da desconstrução do sujeito. A visão de um deus não moral. 
afirmar. Se se afirma tudo, então está incluída nessa afirmação, inclusive, aquilo que Nietzsche mais tem deplorado: a moral cristã. Em que medida este enfrentar de situações adversas reflete o caráter de uma ética cristã, para além de um mero voluntarismo? Por este enfrentamento, se é possível se impor frente ao niilismo, ou seja, se colocar numa posição ativa a fim de que o turbilhão niilista não venha a se configurar numa postura psicológica, da qual nada se cria?

\section{O espírito cristão em Jesus de Nazaré}

Jesus, nas palavras de Nietzsche, a partir de sua prática de vida, deixou o maior de todos os legados à humanidade. Nele o amor cristão vai além da lei e da moral, não é simplesmente um sentimento, mas um sentimento que perpassa a norma. A acolhida do destino com amor, como plenitude vital que atinge seus pontos culminantes. Pois, é no amor que a vida se encontra e se afirma para além de toda e qualquer imputação moral, que age como força estranha. A vida, que em Nietzsche se expressa em suas pulsões instintivas, tanto no ser humano quanto nos animais, contém em si mesma as normas do agir.

O radicalismo de Nietzsche cresceu de acordo com a sua produtividade, vindo a atingir seu auge com seus últimos escritos da maturidade, culminando no Anticristo. Este escrito aparece numa fase tardia de seu pensamento, quando Nietzsche já havia elaborado um juízo acerca do Cristianismo, precisamente em sua concepção de "ethos cristão" e, de alguma forma, já presentes desde seus escritos da juventude, à saber, Introdução teorética sobre a verdade e a mentira no sentido extramoral. A novidade fundamental no Anticristo está, por um lado, na radicalização das críticas de Nietzsche ao Cristianismo e, por outro, na explicitação de sua crítica: um tipo de "vivência cristã" assentado sobre a moral para fundá-la sobre a prática de vida, de onde se origina o espírito cristão genuíno. "O portador da boa-nova" morreu assim como viveu e ensinou - não para "salvar a humanidade", mas para demonstrar-lhe como viver. Seu legado ao homem foi um estilo de vida" 2 (NIETZSCHE, AC, KSA, § 35, VI, 1969, p. 205)

Diante de um espírito cristão autêntico, o filósofo alemão pergunta: "O que foi que Cristo negou? - Tudo aquilo que hoje se chama cristão." (NIETZSCHE, FP, KSA, 1887-9, 16 (87), XIII, 1999, p.517). Pois os rumos que o cristianismo tomau afastou aquele que é considerado o seu sentido mais autêntico, do qual se depreede uma prática, uma ética cristã.

Quanto a esse projeto ético que propomos, ele parece não ser tão evidente em Nietzsche, dado que de sua diversidade de perspectivas, como pensa Scarlett Marton ${ }^{3}$

\footnotetext{
${ }^{2}$ Os fragmentos, cartas e obras de Nietzsche utilizados serão citados pelas suas iniciais como segue: AC: Anticristo, CR: Cartas, FP: Fragmantos Póstumos, GC: Gaia Ciência, GM: Genealogia da Moral. As obras acima são aquelas indicadas na bibliografia, que são aqui citadas a partir do original alemão. Após as iniciais, indicando o autor e a obra, segue a indicação da edição KSA (Kritische Studienausgabe Heraugegeben von Giorgio Colli und Mazzino Montinari), seguida do aforismo, do número (em romano), do ano e da página.

${ }^{3}$ Marton reluta em ver na filosofia de Nietzche uma proposta ética, no entanto considera que "[...] seu pensamento apresenta-se como um sistema em aforismos. Tanto é assim que nele se encontram uma filosofia da natureza, uma filosofia do espírito e uma teoria do conhecimento estreitamente relacionadas" (MARTON, 1990, p. 23). Ora, em nossa pesquisa, extrairmos uma leitura fenomenológica naturalista em Nietzsche, a sensibilidade crítica a uma lógica que perfaz o movimento do espírito e uma atualização na política que se expressa como uma forma de saber que responde à situação do ser humano moderno.
}

FEILER, Adilson Felicio. Nietzsche, o psicólogo da desconstrução do sujeito. A visão de um deus não moral. 
é custoso ver emergir daí uma síntese construtiva. Impõem-se, por isso, duas interpretações sobre a filosofia de Nietzsche: uma metafísica, tributária de Heidegger e outra psicológica que, na interpretação anglo-saxã da filosofia nietzschiana, tem Kaufmann como seu expoente principal. Em nossa pesquisa seguimos esta segunda interpretação, que nos permite reconhecer aquela síntese em Nietzsche como unidades momentâneas, que, ao alcançarem seu auge, se diluem; aquelas bases metafísicas sobre as quais a psicologia clássica outrora se assentava ao identificar o psíquico ao consciente passa a se constituir enquanto ciência da subjetividade na diferenciação entre o consciente e o inconsciente. E, como lembra Oswaldo Giacóia Júnior, é justamente na "[...] dissolução da unidade substancial da alma" (GIACÓIA, 2001, p. 25) que a proposta Nietzschiana se levanta como "[...] um dos principais efeitos de sua crítica da moral, da religião e da metafísica." (GIACÓIA, 2001, p. 26) Com isso, a psique, enfim desembaraçada do fetichismo ocasionado pela moral se apresenta como uma síntese em unidades momentâneas, como pontos culminantes de vida que, ao se diluírem, abrem espaço a novas potencialidades a perfazerem continuamente o processo que serve de base teórica à doutrina científica da subjetividade; em favor da plenitude de si, de sua vida: Lebensfülle. (NIETZSCHE, GC, KSA, § 370, III, 1999, p. 301).

Acreditamos que a perspectiva psicológica pode resultar frutífera no que diz respeito a questão que Nietzsche coloca: a de que tipo de ser humano é capaz de viver neste mundo moderno, um ser humano não submisso aos ditames do turbilhão niilista. Pois o niilismo é teoreticamente possível, porém psicologicamente impossível, ou seja, as instituições criadas pela sociedade são importantes na medida em que impedem com que se pense no niilismo e assim não se venha a nada criar, no dizer de Nietzsche, a nada querer. Qual o caminho, apontado por Nietzsche, para enfretar o niilismo?

\section{Uma ética afirmativa frente ao niilismo}

A inversão de todos os valores é detectada por Nietzsche a partir da renúncia à vida egoísta na cruz de Jesus; esta atitude de renúncia não representa tensão convulsiva, nem covarde auto-humilhação como Nietzsche tenha receado, mas coragem e culminância da força de afirmação da vida (KÜNG, 1976, p. 345). Assim como Walter Kaufmann, seguindo a leitura de Thomas Mann, considera "(...) Nietzsche como o último filho do Romantismo" (KAUFMANN, 1968, p. 15), dentro desse movimento temos no Anticristo a sua expressão mais acabada. E é justamente o Cristianismo da primitiva comunidade cristã, cuja imagem de Cristo carece de base nas fontes, o alvo das críticas de Nietzsche. Razão pela qual nos perguntamos como o Cristianismo inspirado na vida e ensinamentos de um supliciado e aparentemente fracassado pode alcançar dimensões tão universais. Isso se deve aos Com-Jesus, sobretudo, com a sua divulgação do Cristo pós-pascal ${ }^{4}$, o alvo das críticas de

\footnotetext{
${ }^{4}$ A ressurreição de Jesus permanece apenas um evento real para a fé, pois mesmo o Novo Testamento não apresenta nenhuma referência sobre alguma atividade de Jesus entre a sua morte e a ressurreição. (Cf. KÜNG, 1976, p. 320).
}

FEILER, Adilson Felicio. Nietzsche, o psicólogo da desconstrução do sujeito. A visão de um deus não moral. 
Nietzsche. Por isso, o Anticristo, conforme Reto Winteler5(WINTELER, 2009, p. 229), é considerado o primeiro livro de uma completa transvaloração dos valores de Nietzsche, passando por uma crítica ao ressentimento presente na primeira comunidade cristã, que "(...) não compreendeu o principal, [...] a liberdade, a superioridade sobre todo sentimento de ressentiment [ressentimento]" (NIETZSCHE, AC, KSA, §, 40, VI, 1999, p. 213), porém não em Jesus. Ora, na medida em que o espírito do Cristianismo se distingue por uma atitude de encorajamento ético, ao invés de julgamentos morais, de uma prática de vida que reconcilia, ao invés de uma lei que divide, se erige como religião da liberdade. Foi esta prática de vida, implicada numa dimensão de totalidade, que ele mesmo veio inaugurar, "[...] apenas a prática cristã, uma vida tal como a viveu aquele que morreu na cruz, é cristã" (NIETZSCHE, AC, KSA, § 39, VI, 1999, p. 209).

Distante de toda e qualquer forma de ressentimento, o princípio do qual Jesus parte é o de, não se determinar por nenhuma das partes, mas se elevar para além delas, e, ao mesmo tempo, as incluir e elevar num nível superior. Por essa razão, o que move a reflexão do filósofo de Naumburg, em grande parte, é a busca de uma elevação da cultura, que acabou sucumbindo a valores deletérios, incapazes de encarrar o niilismo de frente. Frederick Copleston em seu trabalho Nietzsche Filósofo da Cultura diz que "[...] Nietzsche preocupa-se, em primeiro lugar, com a elevação do homem a um tipo superior; [...] é uma filosofia assertiva, exortatória e dinâmica. Pretende uma transmutação de valores com o fim de conseguir aquilo que julga ser a verdadeira cultura" (COPLESTON, 1979, p. 54). Copleston, reflete o que o filósofo alemão, em última análise, entende por cultura,: “[...] um processo de vida, natural, original, criador e genuíno, e não um conjunto de conhecimentos dessa natureza, mas tais conhecimentos não devem considerar-se essenciais" (COPLESTON, 1979, p. 59). Caso tais conhecimentos vierem a ocupar o lugar central em nossas reflexões, estaremos contribuindo para que a cultura venha a sucumbir.

O contexto em que Jesus surge é de plenas esperanças messiânicas; com isso, quem quer que surgisse com pretensões de liderança, despertaria o ânimo e a curiosidade. Jesus criticou o formalismo da lei judaica, no entanto também aumentou o rigor da lei ao exigir de seus seguidores obediência incondicional; Ele não veio promover uma revolução político-social, mas uma subversão pessoal a partir do coração humano com reflexos para a vida social.

O que Jesus fez foi não apenas não se deixar determinar por alguma parte, mas, muito mais que isso, ensinou isto ao seu povo. $O$ que ele introduziu, foi uma prática de vida, de modo que "[...] - seria possível, com alguma tolerância de expressão, chamar Jesus de 'espírito livre' - ele não faz caso do que é fixo: a palavra mata; tudo o que é fixo mata. $O$ conceito, a experiência de vida, no único modo como ele a conhece, se opõe a toda a espécie de palavra, fórmula, dogma, fé, lei. Ele fala apenas do que é mais íntimo: “vida', "verdade', 'luz"” (NIETZSCHE, AC, KSA, § 32, VI, 1999, p. 204).

Essa dimensão do não deixar-se fixar em nada, de estar aberto ao devir, ao movimento, faz de Jesus o criador de um ethos singular, o que acentua o aspecto

\footnotetext{
${ }^{5}$ Em seu comentário a respeito do Anticristo, Winteler diz que: "Ao invés de perguntar pelo que impediu a conclusão de todo o título da obra, deveria ser tomada primeiramente uma vez a definição de Anticristo para toda a transvaloração dos valores" (KÜNG, 1976, p. 230).
}

FEILER, Adilson Felicio. Nietzsche, o psicólogo da desconstrução do sujeito. A visão de um deus não moral. 
inconfundível de Jesus, outrora e hoje. Tal ethos comunga do devir heraclitiano porque Heráclito tem o mérito de tornar cônscio o movimento infinito de forças, e a contradição universal que daí deriva. A vida compreendida enquanto força, em Nietzsche, revela o seu caráter trágico e que, no destino, encontra a sua expressão máxima; um destino que se vincula a uma dialética cristã, cujo pensamento se realiza em termos de justificação, redenção e reconciliação (KRELL, 1986, p. 28).

Em Jesus, essa dialética tem como ponto de partida a imediatidade do contexto em que viveu, de modo que toda espécie de fixações, como o dogma e a lei, encontram nele uma instância crítica.

Contudo, como membro de um contexto judeu, Jesus foi um observante da lei e dos seus costumes, porém não deixou-se determinar por elas. Não teve a intenção de "[...] redimir os 'homens', mas para mostrar como se deve viver. A prática foi o que ele deixou para a humanidade" (NIETZSCHE, AC, KSA, § 35, VI, 1999, p. 207): na prática Jesus reconcilia o imediato e a crítica, ao mesmo tempo. Todo o projeto de Jesus foi o de levar a humanidade a assimilar uma prática que enfatize o seu valor mais alto: a vida, para além de toda fixação, como reconciliação plena. Em que aspecto a prática de Jesus pode constituir em antídoto de superação do niilismo?

\section{A afirmação como o maior dos pesos}

Para além de suportar aquilo que é necessário, o amor fati envolve amar o seu próprio destino, sem se amparar em falsas seguranças. Por isso, consiste em abraçar ativamente o destino que afirma o caráter trágico do mundo que retorna eternamente, e nesse retorno, o amor não determina o valor dos objetos, mas os transfigura ao lhes outorgar valor, ou seja, transforma o valor passado de seus objetos, transvalora-os. Esta outorga de valor aos objetos é tipicamente agápica; é amar não apenas aquilo que é necessário, mas aquilo que é mais pesado e que retorna, o que equivale a uma transfiguração de si e de sua existência, uma trágica afirmação daquilo que há de mais árduo no destino para viver em plenitude no presente. Em relação a este eterno retorno aproximamos o projeto de Nietzsche ao do estabelecimento de uma nova religião - uma religião baseada num Deus nãomoral, afeita a uma radical interpretação da existência a partir do valor da vida. Sucumbir a valores deletérios é prostrar-se diante de ideias que sacralizam a verdade e a bondade e que hostilizam a vida. Não basta guardar-se de sucumbir àqueles mecanismos sociais niilistas que procuram manter evidente o aspecto teórico do niilismo. É preciso encarrar de frente o niilismo psicológico sem deter-se nele, mas superálo, tal como um salto no abismo, de modo a se atingir o outro lado. $O$ lado do grande sim à vida, o lado que afirma - amor fati - " $(. .$.$) é preciso ainda livrar-se da$ culpa e da má consciência. Nessa empreitada, que seja dito em adendo, celebram em Nietzsche o filósofo da afirmação jubilosa, esquecendo talvez que o amor fati é, antes de mais nada, a aceitação incondicional do sofrimento como parte integrante da existência" (MARTON, 2004, p. 222).

Portanto, o oposto ao movimento nadificador do niilismo, seja em sua forma teórica ou psicológica. Werner Stegmaier, sobre a auto - superação do niilismo, lembra que, em Nietzsche, este é um problema que cabe a cada um lidar: “[...]

FEILER, Adilson Felicio. Nietzsche, o psicólogo da desconstrução do sujeito. A visão de um deus não moral. 
enfrentá-lo sem reservas, levá-lo ao extremo a partir de si mesmo" (STEGMAIER, 2013, p. 256).

Na tragédia se descobre o valor da plenitude da existência; nela nada escapa: a saúde e a doença, a alegria e a tristeza, a vida e a morte, que, em sua tensão, dá sentido à vida, pela constituição de redes potenciais resultantes das polaridades em contraste. Estes polos contrastantes, em sua tensão constante, são abertura à plenitude vital, cuja meta é a liberdade, que é comunhão com o todo, amor fati, sublimação no espírito universal, que é vontade de vida. Desse modo, o Cristianismo não pode ser concebido como uma teoria da qual demanda uma prática, “[...] um conceito fora, uma única realidade em seu lugar - [...] uma religião não só depende de erros, mas inventiva até genial apenas em erros nocivos, que envenenam a vida e o coração" (NIETZSCHE, AC, KSA, § 39, VI, 1999, p. 210), mas uma prática que surja do coração, de um ethos, da vida compreendida em sua plenitude.

A tragédia, um modo de reflexão que nos ajuda a revelar as contradições internas representadas numa forma de vida, a experiência do terror que alerta para a consciência de nossos erros. Em Nietzsche, tal vontade se apresenta como vontade de potência, como vitalidade eterna que se plenifica a cada instante na forma de pontos culminantes de potência pelo movimento do eterno retorno que é chegar a ser o que se é. Tudo é finito: somente o tempo é eterno; assim, cada instante retorna infinitas vezes, e traz a marca da eternidade. Há na visão trágica de Nietzsche um acento ao caos criador que faça frente ao movimento do retorno da consciência moral, a máconsciência. Nietzsche desconstrói o sujeito pela afirmação de um mundo governado por um Deus não moral. Aquele Deus que afirma a vida até as últimas consequências. Portanto, que não sucumbe ao turbilhão nadificador do mundo, mas anela por sempre mais força, sabendo que o que se viveu se viverá uma série interminável de vezes, e, a cada instante vivido pontos sempre mais culminantes de potência se alcançam.

Este traço psicológico de Jesus, em acolher o destino com amor e indiferença, faz da sua prática o seu distintivo enquanto projeto original do Cristianismo, depois, de alguma forma, falsificado pela tradição cristã, por não centrar-se mais em seu tipo, sua psicologia, e sim apenas nos seus atos, gestos e palavras. É com este Cristianismo genuíno da prática de Jesus que Nietzsche se mostra simpático, tal como Heinrich Köseliz se expressa a Nietzsche em uma carta de agosto de 1881: "Eu seria um homem muito melhor se tivesse tomado o Cristianismo mais a sério" (NIETZSCHE, CR, KSA, 1981, p. 179). O tipo Jesus é valorizado por Nietzsche pela sua psicologia que inspira uma prática, por ser aquele em que a estaticidade não tem espaço, em que tudo é dinâmico. Neste sentido, o inevitável eterno retorno deve "[...] anelar pelas virtudes criadoras de um niilismo ativo" (GIACÓIA, 2014, p. 152). como niilismo que afirma a vida. Como perpétuo desenvolvimento do inacabado, o eterno retorno do mesmo é diferente do idêntico, não é um ciclo temporal que se repete, mas faces complementares de uma mesma realidade que se alternam infinitamente numa aspiração romântica à plenitude. Aspirar à plenitude é, ao mesmo tempo, aspirar ao peso mais pesado. É querer que aquilo que se viveu se repita numa séria interminável de vezes, as coisas mais difíceis e, aparentemente, sem sentido, como é o caso da moral cristã. Contudo, ter que afirmar a moral cristã, juntamente com tudo o que inspira submissão, fraqueza e decadência não

FEILER, Adilson Felicio. Nietzsche, o psicólogo da desconstrução do sujeito. A visão de um deus não moral. 
representaria uma aporia, ou, até diria, um contrasenso? Nietzsche, com isso não estaria traindo seu próprio propósito se superação? $O$ afirmar nietzschiano é a meta, o propósito, e nada está para além deste. Continuamente se aspira a mais, e neste aspirar se encontra o único sentido, num retorno infindável. $O$ eterno retorno é o destino, o resultado de nossa própria atividade que colhemos o que vimos semeando, num processo infindável, governado pela contingência da prática do criar.

\section{Conclusão}

O que basicamente caracteriza o amor fati é a dimensão das inclinações do desejo de plenitude, de acolher o destino, nem resignação passiva, mas amor; nem causa ou finalidade, mas fatum. É a aceitação amorosa do que vem, o sim à vida que se quer e se acolhe com abertura jubilosa. Contudo, tal acolhida não consiste na unidade de um todo indiferenciado, mas mantém a diferença, a alteridade, pela afirmação da individualidade; e para afirmar o indivíduo, requer-se o seu diferente: o outro, como polo oposto da luta, num caminho sempre aberto, tal como se caractaeriza o Romantismo.

A filosofia romântica tem como uma de suas características principais a de ser uma filosofia de plenitude, portanto aberta. Essa abertura se dá graças à reconciliação entre a razão clássica e a mitologia grega como unidade entre razão e sentimentos, entre filosofia e mitologia. É, nesse sentido, um projeto de estabelecimento de uma filosofia que faz da força, do sentimento e da arte, a plenitude da vida, que quebra os moldes dos limites da finitude, característica típica dos românticos. A vida, neste sentido, revela o seu poder místico, que se traduz como tragédia; aquele sentimento de angústia, típico da figura histórica de Jesus de Nazaré retratado por Nietzsche.

A filosofia anticristã de Nietzsche mantêm um acento no ethos cristão singular como prática de vida, seja no sentido da aproximação de Deus ao mundo, pela mediação entre a filosofia e a teologia, seja pela crítica à moral deontológica, em nome das inclinações vitais, um espírito que se torna livre para culminar no nada (LÖWITH, 1987, p. 471). O nada, aqui, entendido diz respeito a nenhuma realidade externa que se visa alcançar, pois se existisse, segundo Nietzsche, já teria sido alcançado. Por isso, é um ateísmo honesto (LÖWITH, 1987, p. 471), fundada num Deus não moral, um nada que afirma a vida como instante máximo e pleno. É um ethos como maximização e plenitude da vida até o seus pontos culminantes. A maximização da força se vive a cada instante de plenitude, num percorrer infindável de instantes que se superam. 


\section{Referências:}

COPLESTON, Frederick. Nietzsche. Filósofo da cultura. Porto: Livraria Tavares Martins, 1979.

GIACÓIA JÚNIOR, Oswaldo. Nietzsche como psicólogo. São Leopoldo: Editora Unisinos, 2001.

- Nietzsche. O humano como memória e como promessa. 2a ed. Petrópolis: Editoras Vozes, 2014.

KAUFMANN, Walter. Nietzsche, philosopher, psychologist, antichrist. Princeton: Princeton University Press, 1968.

KRELL, David Farrel. Postponements: woman, sensuality, and death in Nietzsche. Blowington: Indiana University Press, 1986.

KÜNG, Hans. Ser cristão. Rio de Janeiro: Imago, 1976.

LÖWITH, Karl. Nietzsche. Stuttgart: J. B. Metzlersche Verlagsbunchhandlung, 1987.

MARTON, Scarlett. Nietzche: das forças cósmicas aos valores humanos. São Paulo: Brasiliense, 1990. . A irrecusável busca de sentido. São Paulo: Ateliê Editorial, 2004.

NIETZSCHE, F. W. Der Antichrist. In: COLLI, von Giorgio; MONTINARI, Mazzino (Herausgegeben). Kritische Studienausgabe in 15 Bänden. München: Taschenbuch Verlag de Gruyter, 1999. Bd. 6.

- Nachgelassene fragmente: herbst 1887 bis märz 1888. In: COLLI, von Giorgio; MONTINARI, Mazzino (Herausgegeben). Achte Abteilung. Berlin: Walter de Gruyter, 1970. Bd. 2.

. Briefwechsel Kritische Gesamtausgabe. In: MULLER-BUCK, Renate; SCHMID, Holger (Ed.). Nietzsche Briefwechsel: Kritische Gesamtausgabe: Nachbericht Zur Dritten Abteilung: Briefe Von Und an Friedrich Nietzsche 18801884: III 7/1. Dritte Abteilung. Berlin: Walter de Gruyter, 2004. Bd. 7.

- A Gaia Ciência. Trad: Paulo César de Sousa. São Paulo: Companhia das Letras, 2000.

Genealogia da Moral. Uma polêmica. Trad: Paulo César de Sousa. São Paulo: Companhia das Letras, 2001.

F. W. O anticristo, maldição do cristianismo e Ditirambos de Dionísio. Trad: Paulo César de Sousa. Companhia das Letras: São Paulo, 2007.

. Fragmentos Póstumos: 1887-1889. Vol VII. Trad: Marco Antônio Casanova. Rio de Janeiro: Gen/Forense Universitária, 2012.

STEGMAIER, Werner. As linhas fundamentais do pensamento de Nietzsche. Petrópolis: Editora Vozes, 2013.

Autor(a) para correspondência: Adilson Felicio Feiler, Universidade do Vale do Rio dos Sinos, Av. Unisinos, 950 - Cristo Rei, CEP 93020-190, São Leopoldo - RS, Brasil. afeiler@unisinos.br 